\title{
The Impact of the Electoral System on Political Campaigning: Are Candidates for the Council of States More Moderate than their Fellow Candidates for the National Council? ${ }^{1}$
}

\author{
AndReAs LADNER \\ University of Lausanne
}

\begin{abstract}
It is commonly believed that majority voting enhances parties to cluster around the centre of the political space, whereas proportional systems $(P R)$ foster great ideological divergence. The theoretical arguments for these expectations go back to the work of Downs (1957) and Duverger (1954). More recent studies, however, produced quite contradictory empirical findings. In this paper I will test whether similar arguments hold true for the positioning of candidates campaigning in different electoral systems. The elections for the two chambers of the Swiss Parliament and the data from the Swiss Electoral Studies (SELECTS) and the Swiss Voting Advice Application (VAA) smartvote offer an excellent - almost laboratory like - opportunity to do so empirically. The analyses show clearly, the theoretical claims that majority voting necessarily fosters more moderate positions find no support. The candidates for the Council of States, elected in a majority system, are not more moderate than their fellow party candidates for the National Council which are elected in a PR system.
\end{abstract}

Keywords: Electoral systems, PR voting, Polarization, Campaigning, VAAs

The impact of the electoral system on the positioning of the parties and candidates in the course of campaigns (and afterwards) is an intensely debated question in electoral research and parliamentary studies. It is commonly believed that majority systems enhance parties to cluster around the centre of the political space, whereas proportional systems (PR) foster greater ideological divergence. Similar expectations can also be formulated for candidates provided that they have the possibility to position themselves strategically. The theoretical arguments for these expectations are grounded in Downs' (1957) theory of the median voter and Duverger's (1954) law which claims that majority voting promotes two party systems. More recent studies, however, brought forward quite contradictory empirical findings (Dow 2001, 2010, Ezrow 2008, Curini/Hino 2012).

The Swiss political system and the data from the Swiss Electoral Studies (SELECTS) together with data from the Swiss Voting Advice Application (VAA) smartvote ${ }^{2}$ offer an excellent opportunity to address this question empirically. ${ }^{3}$

\footnotetext{
${ }^{1}$ Special thanks go to the three anonymous reviewers whose comments considerably improved the quality of the paper.

${ }^{2}$ See www.smartvote.ch. For a more detailed description of the tool see, for example, Ladner (2012).

${ }^{3}$ For a first attempt to test the usability of VAA data to address this question see Ladner (2014). Voting Advice Applications (VAAs) not only provide voters with information about parties and candidates running for elections, they also gather a huge amount of information about their users and the parties and candidates they are supposed to vote for. This information can be, as it is argued in this earlier contribution, of outmost interest for political scientists
} 
Not astonishing for a federal country, Switzerland's Parliament consists of two chambers: the National Council, where the 26 subnational units, the cantons, are represented according to the number of inhabitants and the Council of States - the "federalist" chamber - where the cantons are represented regardless of their size with two seats each. The two chambers are in terms of competences of equal importance ("symmetric bicameralism") and the elections for both of them take place the same day in the same constituencies (the cantons). An important difference, however, is the two distinct electoral systems ("incongruent bicameralism") in use: PR for the National Council and majority voting for the Council of States.

As for the data, SELECTS not only provides us with a representative sample, but includes also a comprehensive candidate survey. ${ }^{5}$ The VAA data of smartvote furthermore enlarges the variables about the candidates' political positions and brings in the campaign orientation which is addressed in our theoretical expectations. The nearly 3600 candidates running for the two houses have very strong incentives to present themselves on smartvote which increases the participation rate. And, they do it - if they want to get elected - with the voters they have to address in mind. It is here where the strategic considerations, step in. It makes a difference if you need almost half of the electorate or a limited percentage only. Since the users (voters) of smartvote reveal their political positions on the basis of the same questions, we are able to measure the distance between the candidates and different groups of voters directly. It is thus the quality and the quantity of the data and the instrumental use of the VAA by the candidates which lead to a promising research setting.

I shall start this paper by presenting the theoretical considerations behind the questions addressed and the empirical findings so far. Then, I will introduce the context of analysis and present the findings. The paper ends with a conclusion and a roadmap for further research.

\section{Theoretical considerations and empirical findings so far}

Analyzing the impact of electoral systems on party systems and the positioning of the parties and candidates belongs to the core interests of political scientists. It is generally believed that the electoral system - which can be engineered and tailored by people matters and produces specific, more or less adequate outcomes. ${ }^{6}$

The impact of the electoral systems in our context operates in a twofold manner. Directly, on the political positions of parties and candidates and indirectly, through the number of parties, which itself has an influence on the positions of the parties and candidates (see Figure 1).

The arguments behind such a conceptualization go back to authors like Duverger and Downs. According to Duverger's law a majority vote in one ballot leads to a two-party system, whereas proportional representation leads to a multiparty system. A majority vote on two ballots, finally, is conducive to a multiparty system with the parties inclined towards forming coalitions (Duverger 1954). ${ }^{7}$ For Downs (1957) it is the median voter

\footnotetext{
${ }^{4}$ The only exception is the canton of Appenzell-Innerrhoden where the representative in the Council of States is elected in April prior to the national elections in October at the Landsgemeinde.

5 The survey is part of the Comparative Candidate Survey CCS (see http://www.comparativecandidates.org).

${ }^{6}$ In this perspective, the electoral system is seen as an independent variable and not as a consequence of preexisting cultural or political circumstances.

${ }^{7}$ In the majority elections for the Council of States there are also two ballots possible. The candidates, however, try to win the first ballot and position themselves accordingly.
} 
Figure 1: Direct and indirect effects of the electoral system on the political positions of parties/ candidates

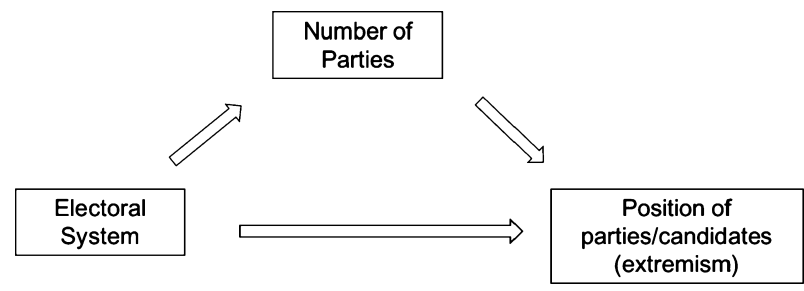

mechanism which motivates parties in a two party system to opt for a position in the centre of the political spectrum where the crucial voter needed to get more than fifty per cent of the votes is likely to be found. The more recent literature is nicely summarized in Ezrow (2008: 482ff.) and Ladner (2014). Interesting to note thereby is the increasing reach of the theoretical arguments which are no longer limited to parties and party systems only.

Cox (1990) claims in his spatial modelling study that proportional electoral rules exert centrifugal incentives that motivate parties to present non-centrist policy programs. In a proportional system, parties are to a lesser extent forced to maximize votes (Dow 2001) than in a majority system, where disproportionality is high and the winner takes it all. It is in the latter systems where parties have to cluster around the centre in order to win, whereas in the former they are freer to bring forward their true policy beliefs and still get a proportional share of the seats. Therefore more extreme party positions are more likely to occur in PR.

As for the indirect effect, Cox (1990) concludes that the greater the number of competitors in a political system is, the stronger are the expectations that some of these parties will present non-centrist positions. Merrill and Adams (2002) argue very similarly that the vote-seeking politicians' centrifugal incentives grow stronger when the number of parties increases. Since the number of parties is presumably higher in PR systems, it is again PR constituencies being more often confronted with party extremism.

This way of argument, however, is questioned by other contributions. Interesting to note, for example, the work of Sartori (1976) which makes for highly fragmented party systems a distinction between segmented multipartism and a polarized multipartism, which means that there can also be party systems with more than two (or three) parties where party competition is clustered around the centre. In a similar vein, Green-Pedersen (2004: 326) insists that if there is a strong centre party, the chances to find a centripetal party competition are as high as in a two-party-system. Finally, it was already Hans Daalder (1984) who claimed that it is more reasonable to believe that in systems with three or more parties (if there is at least one party having a position between the others) there might be centrifugal and centripetal tendencies in party competition. It could, for example, for smaller parties well be the case that maximizing votes are less important than being included in a coalition which can take place on the left, on the right or in the centre (Schoefield et al. 1999). There have also been attempts to introduce strategic incentives related to party activists. Some party activists - holding more extreme positions - provide campaign resources such as money and time (Miller/Schoefield 2003). Another argument stresses the strategic implications of 'valence' dimensions of party evaluation, that is, dimensions related to voters' impression of party elites' competence, honesty or charisma (Stokes 1963). Valence-disadvantaged parties have electoral incentives to differentiate themselves on policy grounds because if they present centrist policies that are similar to 
those advocated by valence-advantaged parties they will have no chances to be successful (Shoefield/Sened 2005).

The empirical evidence regarding the impact of PR on party extremism is ambiguous. Dow (2001) by analyzing the spatial dispersion among parties and candidates in the majoritarian electoral systems in Canada and in France and the highly proportional systems in the Netherlands and Israel finds that parties and candidates in the majoritarian systems are located closer to the center of the distribution of voters. He comes to the same conclusion nearly a decade later by looking at thirty-one electoral democracies: Proportional systems support greater ideological dispersion and party extremism (Dow 2010).

There are, however, also studies which point in the other direction. Curini and Hino (2012) conclude that hypotheses derived from electoral systems and from the number of parties find little empirical support when it comes to explaining party system polarization. They discuss other variables such as expectations of coalition formation and the role the elections play, for example in relation to the presidential elections. And Ezrow (2008) finds no evidence at all that average party policy extremism increases under proportional representation, nor that policy extremism increases in countries that feature a large number of parties.

In a nutshell, there are strong arguments that PR fosters extremism either directly or indirectly through more parties or candidates, but there are also arguments that PR can go hand in hand with more moderate positions. Parties are more than catch-all (Kirchheimer 1965) or electoral (Panebianco 1988) parties. They have a past and they belong to ideological families which has an impact on their marge de manæuvre when it comes to defining their political positions.

And finally, parties, in order to be successful, have to respond to the expectations of the electorate which might also change over time or follow different logics to decide between parties or candidates. Here, the questions are: Are voters really clustered around the centre of the political spectrum? Do they vote for parties and candidates having exactly the same political positions as they have (proximity voting) or is more important that they are on the same side of the political spectrum (directional voting, see Rabinowitz/Macdonald 1989)? Are there strategic reasons to favour candidates with more extreme positions?

\section{Methodological questions, research context and hypotheses}

Although, the research question to answer is quite simple and straight forward, it is far from easy to find adequate data, and there are a few methodological problems to tackle. A first concern is the measurement of the dependent variable. Is it sufficient to analyze party extremism on the left-right dimension or should we not rather look at a multi-dimensional political space (see Ezrow 2008: 495)? And, how do we establish the political positions of parties and candidates? Do we rely on expert judgments and on party manifestos, or do we let the parties/candidates position themselves?

Despite the attractiveness of comparative studies on an international level, it is not always easy to control for all the relevant variables. There are problems when it comes to the selection of countries (see also Dow 2010: 360) which might influence the results. And there are important differences as far as the (political) culture is concerned. It is quite often countries with an Anglo-Saxon background, having an electoral system favouring two party system which can be seen as the result of a specific political culture touching upon the very essence of democracy. The process of coalition building and related presidential elections are additional variables one has to control for. 
And finally, we might also be interested to know to what extent party competition can change over time. If the polarization of a party system can vary without any changes in the electoral system or a significant increase in the number of parties, the direct influence of the electoral system is questioned. This calls for a control of the longitudinal dimension as well.

By looking at subnational units (constituencies) - as we shall do in this paper - we can overcome some of the shortcomings of international comparison. Here we can rely on a more laboratory like situation holding important structural, cultural and political variables constant. The elections for the two Chambers of the Swiss National Parliament offer an almost ideal setting: the two chambers have exactly the same competences ("symmetric bicameralism") and the political issues at stake are identical. Their members are elected the same day ${ }^{8}$ and in the same constituencies (cantons). The only important difference is the electoral system and the number of candidates to elect.

The National Council (the People's Chamber) consists of 200 members. The number of seats of the cantons varies according to their population: the canton of Zurich, for example, has 34 seats, the canton of Glarus only one. ${ }^{9}$ It is in the National Council, where party politics take place, and the debates tend to be louder and more controversial. The Council of States has 46 representatives (two from each canton and one from each half-canton ${ }^{10}$ ). ${ }^{11}$ The Council of States is often considered to be more prestigious. Since it is smaller the weight of a single member of parliament is bigger and they are considered to be more (elderly) statesmen than party politician representing the interests of their cantons rather than the party line. The house is therefore often referred to as the "chambre de reflexion".

The electoral system for the National Council is - since 1919 - a proportional system (PR) with open lists. The voters have the possibility to customize their ballot paper by taking candidates from different parties either by using an empty list or by discarding candidates from a party list ("panaschieren"); additionally they can express their preferences for specific candidates by writing down their names twice instead of once ("kumulieren"). In cantons with a large number of representatives a small percentage of the votes will do to get elected. For the Council of States (Chamber of the cantons) an overwhelming majority of the cantons uses a majority system. ${ }^{12}$ Although, the majority systems elections take place in two ballots (absolute majority in the first round, relative majority in the second), a second ballot is usually not expected to take place. The candidates go for a win in the first round and coalition building for a possible second round is unlikely to influence their positioning. ${ }^{13}$ The percentage to get elected in any case

\footnotetext{
${ }^{8}$ In Appenzell Innerrhoden and in Nidwalden the elections for the Council of States take place earlier the same year.

${ }^{9}$ The strongest party in the National Council (after the 2011 elections) is the Swiss People's Party (SVP) with 54 seats (26.6 per cent of the vote), followed by the Social Democrats (SP) with 46 seats (18.7 per cent of the vote), the Liberal Party (FDP.Die Liberalen) with 30 seats (15.1 per cent of the vote) and the Christian Democrats with 28 seats (12.3 per cent of the votes).

${ }^{10}$ Actually there are 20 full cantons and 6 half cantons with one seat only, that is why the total number is 46 and not 52. Apart from that there is no significant difference between half and full cantons.

11 The strongest parties in the Council of States are after the 2011 elections the Christian Democrats (CVP) with 13 seats, followed by the Radical Democrats (FDP.Die Liberalen) and the Social Democrats (SP) with 11 seats and the Swiss People's Party (SVP) with 5 seats.

12 Only the two cantons Neuchâtel and Jura use a PR system, and in the half-canton of Appenzell-Innerrhoden they elect their representative at the Landsgemeinde (assembly).

${ }^{13}$ In 2007, for example, there were second ballots in 5 cantons only. The 2011 elections with 13 cantons going for a second ballot for the Council of States was rather an exception due to an increasing number of candidates from the Swiss People's Party (SVP).
} 
is considerably higher and amounts to 50 or at least well over 30 percent of the votes which is beyond the reach of almost all parties competing.

As for the longitudinal aspect, we are at least able to look at two consecutive elections (2007 and 2011). This can serve as a test for the robustness of the results. Furthermore, the 2011 elections were somehow particular since one party started a huge campaign called the "assault of the Stöckli" to correct its weak representation in the Council of States. The institutional setting, of course, did not change between the two elections.

Taken all together, we are able to analyze the strategies of parties and candidates in about 100 rather independent elections, half of them taking place under PR and half of them under majority rule. Our sample for the elections in 2011 contains 153 candidates running for the Council of States and 3473 candidates running for the National Council, in the 2007 election the respective number of candidates were 141 and 3100 .

Our hypothetical expectations regarding the political positions taken by the candidates for the two houses of parliament can be summarized as follows: Majority voting fosters centrism. Candidates running for the Council of States need to attract a larger part of the electorate and are therefore expected to move closer to the median voter (the centre of the political space). They will have more moderate positions than their fellow party candidates for the National Council.

The data we use to test the hypothesis stem from the Swiss Electoral Studies (SELECTS) and the Swiss VAA smartvote. SELECTS provides us with representative samples of Swiss citizens for the years 2007 and 2011 which allow us to calculate the position of the median voters. SELECTS also contains a candidate survey, which covers roughly have of the candidates running for the two elections. For a more detailed analysis of the political positions we rely on data produced by the VAA. Smartvote is - in order to catch up with the possibilities of the electoral systems - candidate based. This means that every candidate has its own political profile, and the users can not only look up which party is closest to their political preferences, but they also get a list of candidates with the candidates closest to their positions at the top. The candidates reveal their political profile by answering the same questions (issues) as the users. They are - and this is important more or less free to position themselves according to their personal preferences and strategic considerations. The parties try to influence their candidates, especially for the most important questions (party logic), but it is the candidates themselves, which hand in their answers (the logic of the candidates). There are, of course, party specific profiles to be found, but studies analysing the political profiles of the candidates in more detail show a considerable variance within the parties, especially for issues which are not among the core issues of the party (see for example Ladner et al. 2008). The policy positions of the candidates are thus not entirely exogenous and depend on the candidates themselves.

The way the candidates present themselves and the political profile they have on Smartvote is not unimportant, since the tool is very popular and quite influential. More than 80 per cent of the candidates running for both houses present themselves on the website. About 18 per cent of the voters consult the website before voting, and it can be shown, that smartvote has an influence on electoral turnout (Ladner/Pianzola 2010) and on the electoral decisions of the users (Ladner et al. 2010: 113ff., Pianzola 2013). Smartvote covers about 70 issues for each election.

Our research setting and the smartvote data also bear some methodological problems we have to keep in mind. Some candidates (79 candidates in 2011 and 60 in 2007) are running for both houses and there might be a contamination effect. The Council of States, however, is more prestigious so we expect that this will influence the way the candidates 
present themselves politically, at least for those who think they have a real chance to get elected. Candidates from smaller parties which do not have a chance to get elected in majority elections simply use their candidate for the Council of States to attract more attention and to gain more votes for the National Council. Here, the moderating effect of the majority system should not be effective. Another concern is the reliability of the data. The data about the candidates is quite reliable since it covers an overwhelming majority of the candidates. Their self-positioning on smartvote seems to us to be more appropriate to analyze their strategic campaign behaviour than questions in candidate surveys. VAAs are the places where they directly present themselves to their voters, whereas in surveys they are more likely to report the official party line. The data about the users will need some attention. As it has been shown (see for example Ladner 2011: 101f., Ladner/Fivaz 2012: 186f.), it is far from representative. The better educated supporters of left-wing parties are overrepresented and it contains only those which participated in the online survey after the elections. There is likely to be a self-selection bias. The data therefore have to be weighted. $^{14}$

\section{Results}

We start our analysis by looking at the candidates' self-placements on the left-right axis in the SELECTS candidate surveys 2007 and 2011. Figure 2 shows the means for all the candidates of the five biggest parties in Switzerland: the Swiss People's Party (SVP), the Social Democrats (SP), the Liberal Party (FDP), the Christian Democrats (CVP) and the Green Party (GPS). The figure distinguishes for each party between the candidates for the Council of States (squares) and the candidates for the National Council (triangles). The position of the "median voter", ${ }^{15}$ as revealed by the SELECTS voter survey, is at 5.39 for 2007 and 5.16 for 2011 .

Furthest away from the median voter's position respectively from the middle of the political spectrum are not astonishingly the candidates (for both Houses) of the Swiss People's Party on the right and the candidates of the Social Democrats and the Green Party on the left. The candidates of the Green Party, however, slightly moved to the centre in the course of the 2011 elections.

In the 2007 elections, the differences between the candidates for the two different chambers of parliament within each party are only minor. It is only for the Social Democrats where a difference of about half a point on the left-right axis becomes visible with the candidates for the Council of States being more moderate. This, at least, would support our hypothesis, whereas for the other parties the candidates for the Council of State, which are to be elected in a majority system, are further away from their fellow party candidates for the National Council or position themselves very similarly. The results of the 2011 elections do not fully support our hypothesis either, on the contrary. This time, it is the candidates for the Council of States of the Swiss People's Party and the Christian Democrats, which are further away from the median voter position than their fellow party candidates for the National Council. On the left, at least, the candidates for the Council of States are now more moderate in the case of the Green Party and the Social Democrats.

\footnotetext{
14 The weight used is party preferences/vote for parties. The sample to calculate the "median voter" should at least reflect the party preferences of the electorates in 2007 and 2011.

${ }^{15}$ Since the median position on the scale from 0 to 10 is for both years 5 we use the means value instead.
} 
Figure 2: Left-right positions of the candidates for the Council of States and the candidates for the National Council 2011 and 2007 (means and median values) ${ }^{16}$
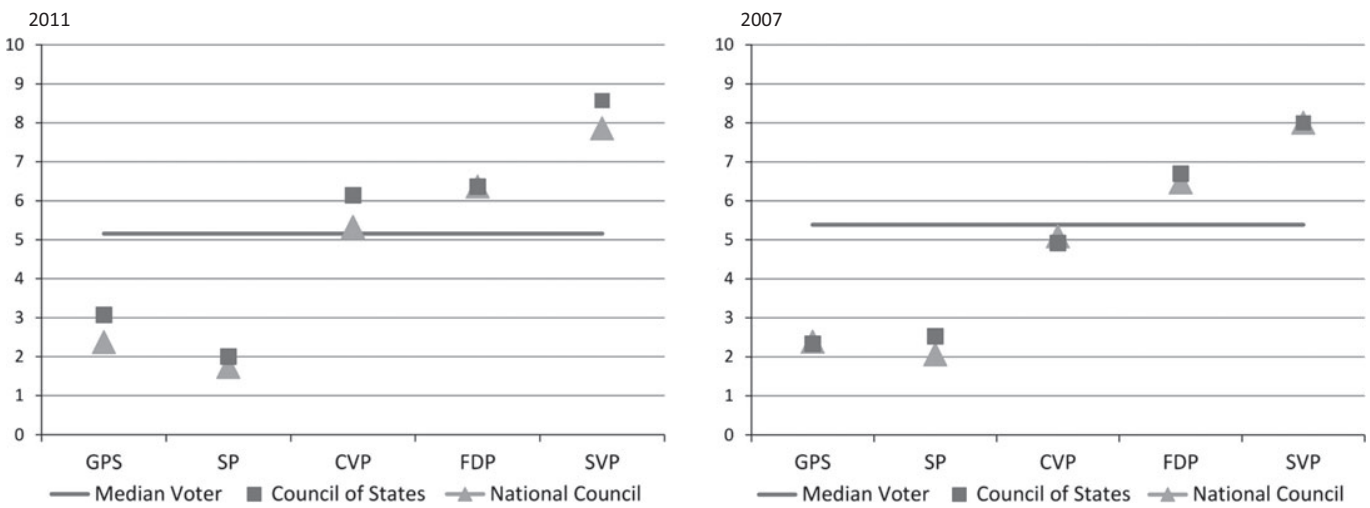

GPS $=$ Green Party; SP $=$ Social Democrats; CVP $=$ Christian Democrats;

FDP $=$ Liberal Party; SVP $=$ Swiss People's Party

N 2011 NC/CS: GPS 184/14; SP 239/12; CVP 168/7; FDP 165/11; SVP 132/7, Voters 1360

N 2007 NC/CS: GPS 261/9; SP 260/17; CVP 200/12; FDP 220/10; SVP 203/15, Voters 2059

If we compare the positions of candidates of the different parties in 2007 and 2011, there is hardly any change for the candidates for the National Council. As for the candidates for the Council of States a shift to the right can be observed for the Green Party, the Christian Democrats and the Swiss People's Party. The candidates of the Greens moved, thus, in the direction of our theoretical expectations whereas those of the two other parties moved into the theoretically wrong direction. For the Swiss People's Party this reflects the radical positions of the well-known party members taking part in the "assault of the Stöckli". ${ }^{17}$ The candidates of the Liberal Party and the Social Democrats moved to the left. Here, it is the Liberal Party, which behaved according to our expectations whereas the Social Democrats did not.

At a first glance, there is thus no strong evidence supporting our hypothesis. More moderate positions of the candidates elected in a majority system do not seem to be the rule. A number of contaminating factors, however, might be responsible for this:

- Limited proportionality for the National Council: Although the national electoral rules clearly state that the members of the National Council have to be elected in a proportional representation system, there are a number of cantons where the number of seats equals one or only very few. Hence, to win a seat demands the majority of the votes or a quite important percentage of the electorate and therefore a campaign strategy which also addresses voters of other parties. In these cantons, there should also be strong incentives for candidates running for the National Council to present more moderate positions.

\footnotetext{
${ }^{16}$ Methodological note: The positions of the candidates in 2011 have been corrected for the distortion caused by a different coding of the left-right axis in the original data files.

17 "Aussault to the Stöckli" refers to the Swiss People's Party's campaign in the course of the 2011 elections. The party tried to improve its representation in the Council of States ("Stöckli") by nominating their best known exponents to run for the elections.
} 
- PR for Council of States: Since the electoral laws for the Council of States depend on cantonal legislation not all cantons use the same electoral system. There are two cantons (JU, NE) which use a PR system also for the Council of States.

- Double candidatures: And finally, there are candidates presenting themselves for both houses, either because they are not sure to get elected to the Council of States or because they use the increased attention the candidates for the Council of States receive to render their candidature for the National Council more successful.

Fortunately, we can deal with these contaminating factors quite easily by concentrating on the seven largest cantons which are Zürich (ZH), Bern (BE), Vaud (VD), Aargau (AG), St. Gallen (SG) and Genève (GE) and Luzern (LU). In these cantons the number of representatives in the National Council varies between 10 for the canton of Luzern and 34 for the canton of Zürich. The number of seats is thus large enough to give all important parties - which are again the Swiss People's Party (SVP), the Social Democrats (SP), the Liberal Party (FDP), the Christian Democrats (CVP) and the Green Party (GPS) - the possibility to win seats if they manage to mobilize their supporters. ${ }^{18}$ As for the Council of States, all seven cantons have majority elections. Although, there are differences in the way the majority is calculated (see Lutz/Strohmann 1998: 104), the percentage of votes needed to win a seat exceeds considerably the circle of the supporters the parties usually dispose of. ${ }^{19}$ And since we concentrate on the candidates of the five biggest parties, all of them can be considered as real candidates since they have at least a small chance to get elected and they have - according to our theoretical expectations - good reasons to defend more moderate positions.

Figure 3 shows the same graphs for the new and presumably better set of candidates. For the 2007 elections, it is the Liberals and the Social Democrats which support our hypothesis. For the 2011 elections, it is only the candidates of the Green Party, which clearly behave according to our expectations. The candidates for the Council of States of the three parties of the right (SVP, FDP and CVP) are further to the right than their fellow candidates for the National Council.

Again the figures reveal no strong trend between 2007 and 2011 in either direction for the candidates of the National Council. Whereas the candidates for the Council of States are clearly moving to the right in the cases of the Greens, the Christian Democrats, the Liberals and also the Swiss People's Party. The candidates of the Social Democrats moved on average to the left.

Except for the Greens in 2011 there is no generally valid and clearly moderating effect of majority elections visible. In the strongly - particularly by the Swiss People's Party contested 2011 elections, right wing parties rather seem to seek their success on the right side of the political spectrum.

\footnotetext{
${ }^{18}$ In the canton of Zürich the percentage of the votes needed to win one seat by its own strength is 2.9 , in Luzern it is 9.1. The Federal Court requests electoral districts with a minimum of ten seats to meet the requirements of PR. A party should be able to win a seat if it reaches about 10 per cent of the voters. The rules of the Federal Court, however, only apply for elections on lower levels.

${ }^{19}$ In LU, AG, SG and VD the majority needed is calculated on the basis of the ballot lists. Here the candidate has to attract 50 percent of the voters plus 1 . In $\mathrm{ZH}$ and $\mathrm{BE}$ the majority is calculated on the basis of the votes given (some voters only write down one name instead of two, empty lines are not considered as votes). Here the percentage of votes is a little bit smaller. In GE the percentage of votes needed is 33.3 (Lutz and Strohmann 1998: 163).
} 
Figure 3: Left-right positions of the candidates for the Council of States and the candidates for the National Council 2007 and 2011, real PR and majority cantons
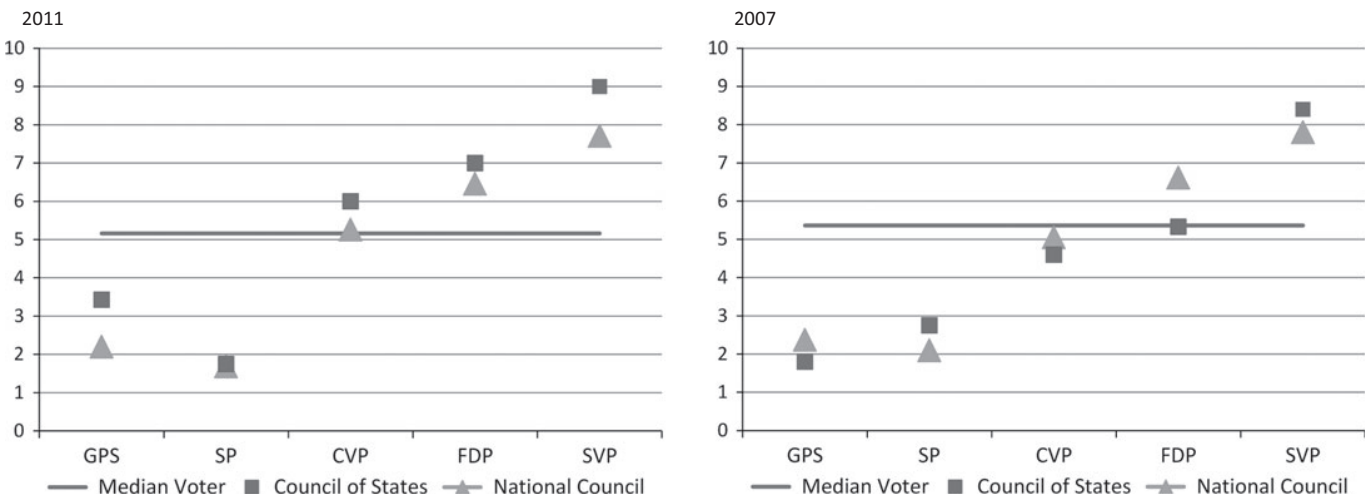

GPS $=$ Green Party; SP $=$ Social Democrats; CVP $=$ Christian Democrats;

FDP = Liberal Party; SVP = Swiss People's Party

N 2011 NC/CS: GPS 114/7; SP 155/4; CVP 101/2; FDP 99/3; SVP 73/4, Voters 907

N 2007 NC/CS: GPS 192/5; SP 167/4; CVP 115/5; FDP 140/3; SVP 122/5; Voters 1278

As already mentioned previously, there is an on-going debate whether the left-right axis adequately measures political differences or whether - following Ezrow (2008: 495) for example - we should not rather look at a multi-dimensional political space? In a next step, we shall therefore expand our measurement of political positions and look at eight different policy dimension used by smartvote to position parties and candidates and compare them to the voter's position. The dimensions combine a number of issues addressed on the website, such as a welfare state, environment, immigration, etc. ${ }^{20} \mathrm{We}$ thus continue continued our analysis with another set of data than the candidate survey and the representative electoral survey SELECTS we used so far and leave the - perhaps too simplistic - one dimensional political space.

The smartvote data bear the advantage that it contains a much bigger number of issues to position, candidates and voters and even more importantly, that the candidates do not consider it as a scientific study about their political beliefs but rather as an important and helpful tool for their campaign. Hence, they present themselves the way they want to be perceived by the voters they try to attract in order to get elected.

Table 1 shows the distance between the candidates for the National Council and the Council of States and the position of the median voter on eight policy dimensions for each of the five parties. The position of the median voter is calculated on the basis of two surveys conducted among the users of smartvote in 2007 and $2011 .^{21}$

Unfortunately, the results of our analysis are still far from supportive for our hypothesis. In general, the average position of the candidates for the Council of States is

\footnotetext{
${ }^{20}$ For a description of the method used see: http://www.smartvote.ch/downloads/methodology_ smartspider_de_CH.pdf (accessed: 9.9.2013).

21 The respondents of these surveys are far from representative. The samples have therefore to be weighted. We use a simple weight based on the party the users voted for only. Hence the vote of the users in the weighted sample equals the electoral results. The median voter position on the eight issue dimensions corresponds to the median position of the weighted sample on these dimensions.
} 
Table 1: Distance of the (average) candidate positions to the median voter's position in eight policy dimensions. Candidates for the Council of States and the National Council in the course of the 2007 and 2011 elections

\begin{tabular}{|c|c|c|c|c|c|c|c|c|c|c|c|}
\hline \multirow[b]{2}{*}{2011} & \multicolumn{2}{|c|}{ GPS } & \multicolumn{2}{|c|}{ SP } & \multirow{2}{*}{$\begin{array}{l}\text { Median } \\
\text { Voter }\end{array}$} & \multicolumn{2}{|c|}{ CVP } & \multicolumn{2}{|c|}{ FDP } & \multicolumn{2}{|c|}{ SVP } \\
\hline & $\mathrm{NC}$ & $\mathrm{CS}$ & $\mathrm{NC}$ & CS & & $\mathrm{NC}$ & CS & $\mathrm{NC}$ & $\mathrm{CS}$ & $\mathrm{NC}$ & $\mathrm{CS}$ \\
\hline $\begin{array}{l}\text { Open foreign } \\
\text { policy }\end{array}$ & 12.5 & 1.6 & 28.1 & 31.3 & 56.3 & 0.0 & -1.6 & -3.1 & -10.9 & -50.0 & -50.0 \\
\hline Liberal economy & 20.3 & -20.3 & -14.1 & -17.2 & 45.3 & 12.5 & 18.8 & 31.3 & 39.1 & 9.4 & 28.1 \\
\hline $\begin{array}{l}\text { Restrictive } \\
\text { financial policy }\end{array}$ & -16.3 & -18.4 & -17.7 & -19.1 & 46.9 & 7.3 & 3.8 & 12.8 & 13.5 & 21.2 & 21.2 \\
\hline Law \& Order & 9.2 & -34.2 & -29.2 & -31.7 & 41.7 & 13.3 & 18.3 & 15.8 & 25.8 & 33.3 & 30.8 \\
\hline $\begin{array}{l}\text { Restrictive } \\
\text { immigration } \\
\text { policy }\end{array}$ & -42.9 & -41.1 & -42.9 & -42.9 & 46.4 & 0.0 & -5.4 & 10.7 & 14.3 & 50.0 & 39.3 \\
\hline $\begin{array}{l}\text { Extended } \\
\text { environmental } \\
\text { protection }\end{array}$ & 30.5 & 31.6 & 23.6 & 23.6 & 65.0 & -5.9 & -16.1 & -26.4 & -33.2 & -37.7 & -53.6 \\
\hline $\begin{array}{l}\text { Expanded welfare } \\
\text { state }\end{array}$ & 30.6 & 31.9 & 30.6 & 38.9 & 55.6 & -8.3 & -11.1 & -27.8 & -22.2 & -30.6 & -33.3 \\
\hline Liberal Society & 10.7 & 14.1 & 15.2 & 15.2 & 57.5 & -14.3 & -23.4 & 3.9 & 5.0 & -16.6 & -25.7 \\
\hline $\mathrm{N}=$ & & 6 & 267 & 7 & & 194 & 8 & 26 & 8 & 164 & 5 \\
\hline $\begin{array}{l}\text { Candidates closer } \\
\text { to median voter }\end{array}$ & 5 & 2 & 5 & 0 & & 7 & 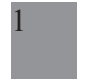 & 7 & 1 & 4 & 2 \\
\hline \multirow[t]{2}{*}{2007} & GPS & & $\mathrm{SP}$ & & $\begin{array}{l}\text { Median } \\
\text { Voter }\end{array}$ & CVP & & FDP & & SVP & \\
\hline & $\mathrm{NC}$ & CS & $\mathrm{NC}$ & CS & & $\mathrm{NC}$ & CS & $\mathrm{NC}$ & CS & $\mathrm{NC}$ & CS \\
\hline $\begin{array}{l}\text { Open foreign } \\
\text { policy }\end{array}$ & 17.9 & 14.3 & 32.1 & 35.7 & 50.0 & 5.9 & 17.9 & 14.3 & 19.6 & -39.3 & -39.3 \\
\hline Liberal economy & -19.1 & -20.6 & -19.1 & -16.2 & 50.0 & 9 & 5.9 & 27.9 & 27.9 & 14.7 & 15.4 \\
\hline $\begin{array}{l}\text { Restrictive } \\
\text { financial policy }\end{array}$ & -15.0 & -16.7 & -20.0 & -23.3 & 43.3 & -2.3 & -0.8 & 15.0 & 10.0 & 20.0 & 20.0 \\
\hline Law \& Order & -27.5 & -32.5 & -22.5 & -20.0 & 50.0 & & 5.0 & 7.5 & 13.8 & 22.5 & 31.3 \\
\hline $\begin{array}{l}\text { Restrictive } \\
\text { immigration } \\
\text { policy }\end{array}$ & -45.8 & -50.0 & -50.0 & -45.8 & 50.0 & -7.9 & -10.4 & -4.2 & -10.4 & 45.8 & 43.7 \\
\hline $\begin{array}{l}\text { Extended } \\
\text { environmental } \\
\text { protection }\end{array}$ & 31.3 & 33.3 & 29.2 & 29.2 & 64.6 & -2.9 & -7.3 & -25.0 & -32.3 & -37.5 & -49.0 \\
\hline $\begin{array}{l}\text { Expanded welfare } \\
\text { state }\end{array}$ & 27.3 & 34.1 & 36.4 & 31.8 & 56.8 & -2.8 & 0.0 & -22.7 & -12.5 & -31.8 & -37.5 \\
\hline Liberal Society & 22.7 & 20.5 & 25.0 & 25.0 & 61.4 & -6.1 & -5.7 & -4.6 & -12.5 & -27.3 & -35.2 \\
\hline $\mathrm{N}=$ & 267 & 7 & 252 & 7 & & 184 & 6 & 263 & 6 & 214 & 8 \\
\hline $\begin{array}{l}\text { Candidates closer } \\
\text { to median voter }\end{array}$ & 6 & 2 & 2 & 4 & & 4 & 4 & 5 & 2 & 5 & \\
\hline
\end{tabular}

not closer to the position of the median voter than the position of the candidates for the National Council. In 2011, there are only six out of possible 40 cases where the candidates for the Council of States are more moderate (see boxes in grey in Table 1): for the 
Liberals this is the case for issues concerning the Welfare State, and for the Swiss People's Party it is when it comes to Immigration and Law \& Order, for example. As for the 2007 elections, the number of cases supporting our hypothesis increases to 13. Still, and apart from the Social Democrats, it cannot be argued that the candidates for the Council of States are generally more moderate. Again, we find evidence that there is room for variation over time. In the 2011 elections, the candidates for the Council of States are even less moderate than in the 2007 elections. Their positioning might thus be influenced by other variables than the electoral system itself.

Since the empirical results fail again to confirm our hypothesis consistently there are two possibilities: either our theoretical expectations were completely wrong or our analysis misses some important elements. One of the basic arguments of our theoretical model is the Downs' idea that the voters are normally distributed around the median voter. It might, however, be the case that the electoral market is segmented and split up in two different camps, one on the right and one on the left of the political spectrum. This possibility finds empirical support by the results of the Swiss Electoral Studies (SELECTS). If we look at the electorate in the elections 2007 and 2011, the distribution of the voters on the left-right dimension is not normal but rather a bimodal (see Lutz 2008, 2012). This is also the case when we look at the users of smartvote.

Following the concept of directional voting (Rabinowitz and Macdonald 1989) people would rather vote for a candidate on their side of the political spectrum than for the one which is closest to them. Considering the fact that for the Council of States the candidates are running for two seats, the electoral competition does not necessarily have to be centripetal. The candidates still have to win a considerable amount of votes to get elected, but they may argue that they rather try to win votes on their side of the political spectrum (either on the left or on the right, for example) and abstain from moving too far to the centre. In fact, in quite a few cantons (especially in the bigger ones with a higher number of parties) there are occasionally split tickets representing the canton, meaning that one representative comes from the right and the other one from the left. Among the seven largest cantons (ZH, BE, LU, VD, AG, SG, GE) there were - between 2007 and 2011 four cantons with a split ticket $(\mathrm{ZH}, \mathrm{BE}, \mathrm{AG}$ and $\mathrm{SG})$ and three (LU, VD and GE) from which the two representatives in the Council of States were on the same side of the political spectrum (Social Democrats and Green Party in VD and GE or Liberal Party and Christian Democrats in LU).

Figure 4 presents the average distances of the two groups of candidates of each party to the median voter and to the median voter of each side of the political dimension, meaning the median (quartiles) of the half of the voters in favor or the median of the half of them against a specific set of policy issues. The graphs clearly show that with one exception the distances of the candidates of the different parties to their respective quartiles are smaller than to the median voter. The only exception is the Christian Democrats, which are for most issues located in the middle of the different positions. Interesting to note more particularly is the fact that for the 2011 elections, all candidates for the Council of States have also been further away from their quartile voters compared to their fellow party candidates for the Council of States. For the 2007 elections at least, the Social Democrats and the Liberals reveal a pattern which supports our hypothesis. Here, the candidates for the Council of States are closer to the quartile voter than their fellow party candidates for the National Council.

The candidates for the two houses obviously do not campaign the way our hypothesis predicts them to do. In most cases the candidates for the Council of States take more 
Figure 4: Average distance of the candidates to median and quartile voters on eight policy dimensions
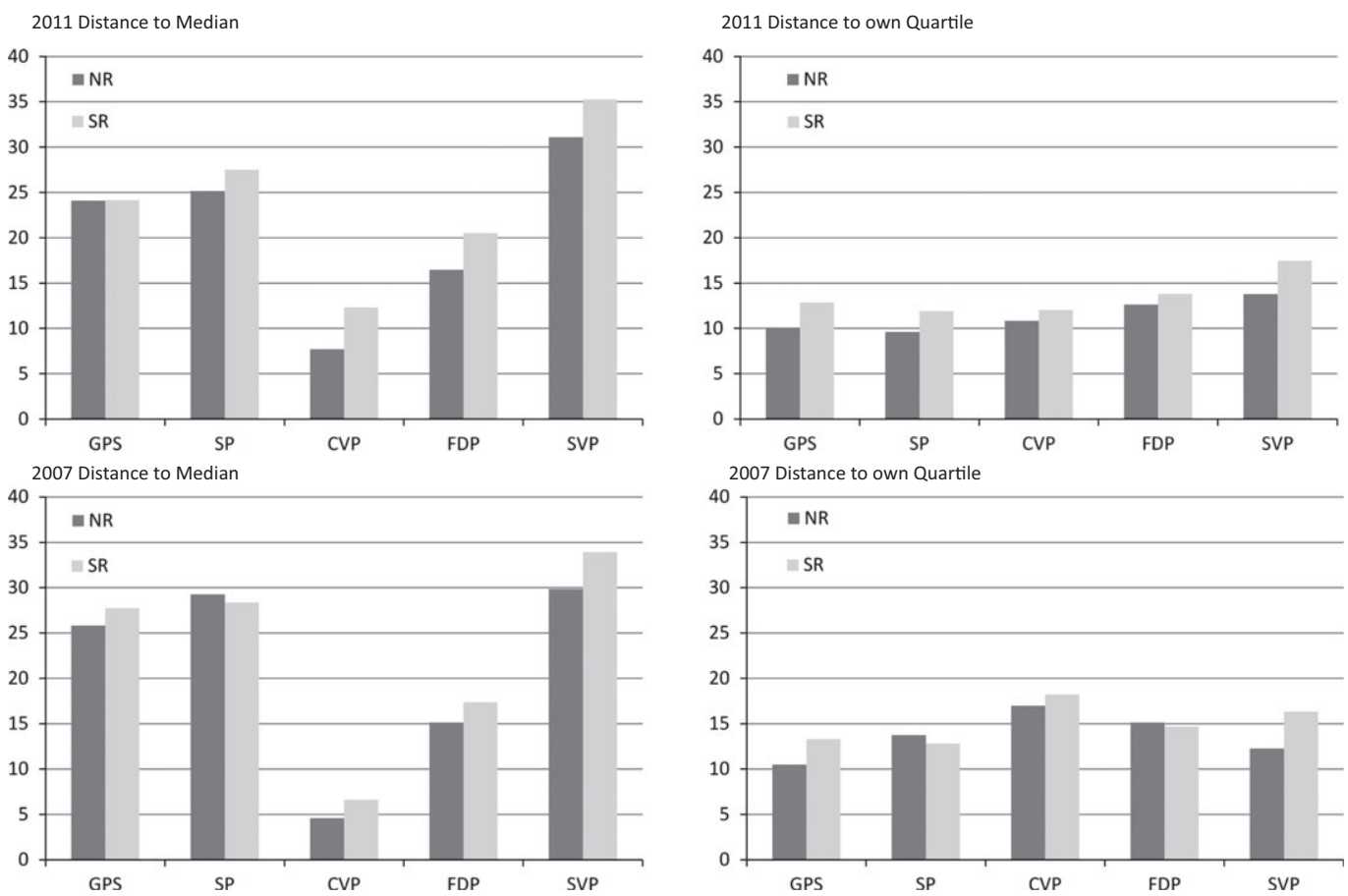

How to read the charts: If the right hand bar is higher, the candidates for the Council of States are less moderate (further away from the median or quartile voter)

Only cantons where real PR elections for the National Council take place: ZH, BE, LU, AG, SG, VD and GE

N 2011 NC/CS: GPS 225/6; SP 267/7; CVP 194/8; FDP 261/8; SVP 164/5, Voters 7900

N 2007 NC/CS: GPS 267/7; SP 252/7; CVP 184/6; FDP 263/6; SVP 214/8; Voters 9180

pronounced positions and are further away from the median voter of all voters or even from the median voter of the voters of their side of the political spectrum. There is no empirical evidence that the higher percentage of votes needed to get elected in a majority system leads to campaign strategies targeting more moderate positions.

There are two other possible explanations which might help to rescue the theoretical expectations, at least partially: Perhaps the general image of the Council of States as the "chamber de reflexion" and the politically less polarized chamber of parliament is not correct anymore, and it could be that it is the more polarizing campaigns which have generally proven to be more successful for the Council of States. If candidates and voters are aware of this, the more extreme positions of the candidates will become rational.

Are the members of the upper chamber, the Council of States, really more moderate than their colleagues in the National Council? The results can be seen in figure 5. After the 2007 elections, the elected members of the Council of States have always been closer to the median voter than the members of the National Council. For the period 2007 to 2011, the image that the Council of States, consisting of the more moderate members of the different parties still holds true. This should have been the reference point for the candidates running for the 2011 
Figure 5: Average distance of the elected members of parliament to the median voters on eight policy dimensions
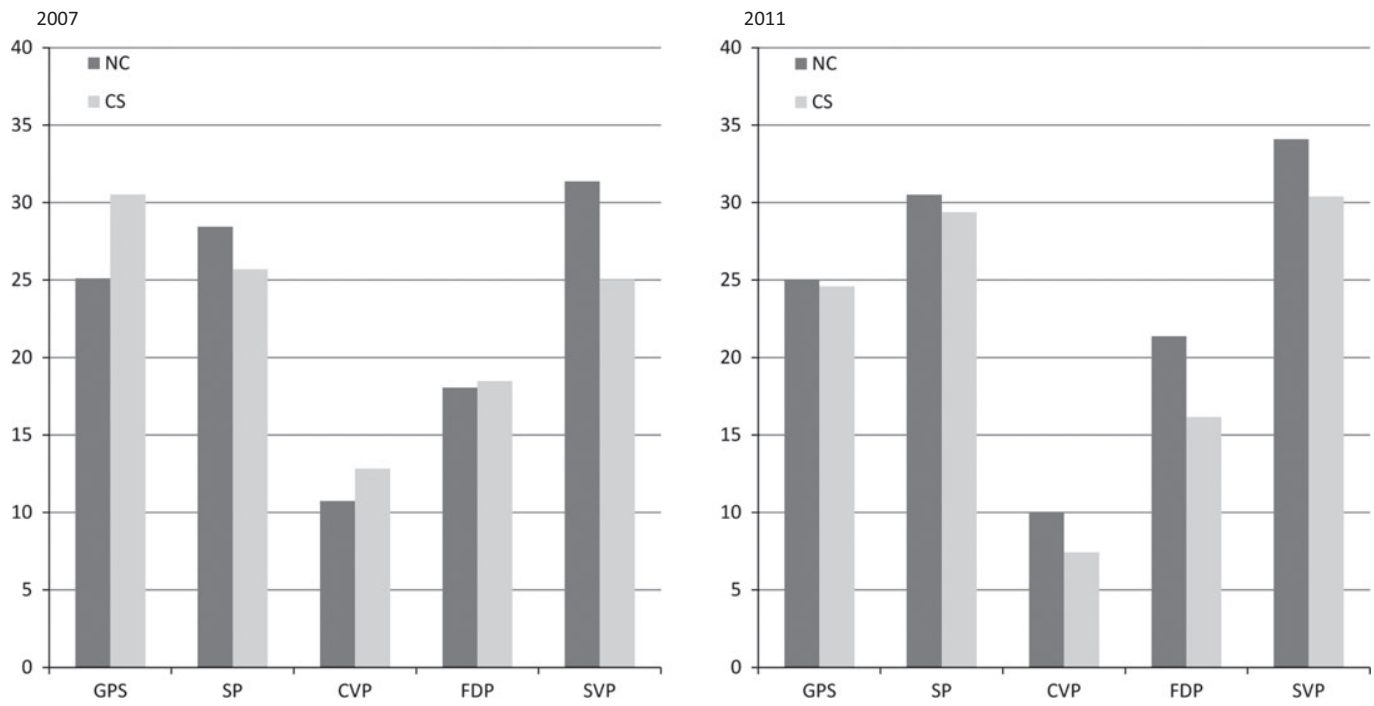

How to read the charts: If the right hand bar is higher, the elected members of the Council of States are less moderate (further away from the median voter)

Only cantons where real PR elections for the National Council take place: ZH, BE, AG, SG, VD and GE

N $2011 \mathrm{NC} / \mathrm{CS}$ : GPS 12/(1); SP 28/5; CVP 11/(1); FDP 16/4; SVP 28/(3) $)^{2222}$ In the seven cantons we are looking at, there is no member of the Swiss People's Party represented in 2011. We therefore take the three members from the other cantons as a point of reference.

Voters 7900

N 2007 NC/CS: GPS 15/2; SP 25/3; CVP 15/2; FDP 16/4; SVP 37/2; Voters 9180

elections. Despite this, they rather took - as we have seen - more extreme positions for the 2011 elections as their party fellow colleagues in the National Council.

After the 2011 elections, the more moderate members of the Council of States are only found in the case of the Social Democrats and the Swiss People's Party. For the other three parties, the elected members of the Council of States are less moderate than their elected colleagues in the National Council. Since the two more extreme parties in the Council of States, the Swiss People's Party and the Social Democrats, have more moderate representatives, the house most probably keeps its more moderate image, as well. Whether this will have an impact on the upcoming elections is far from clear. As for the campaigns, the question is, whether the more moderate or the more extreme candidates of the different parties got elected in each house?

Figure 6 compares, last but not least, the elected members of each party in each chamber with the non-elected candidates. In the National Council the results are quite clear. The elected members of the National Council are - apart from one exception - in both elections, further away from the median voter than their non-elected colleagues. For the Council of States, the pattern is ambiguous. Although there is a slight tendency that the elected members are more moderate, there are also cases where there is no difference (FDP and CVP in 2011) or where the opposite is true (SP 2007 and GPS 2011). For the 
Figure 6: Average distance of elected and non-elected candidates to median voters 2011 National Council 2011 Council of States
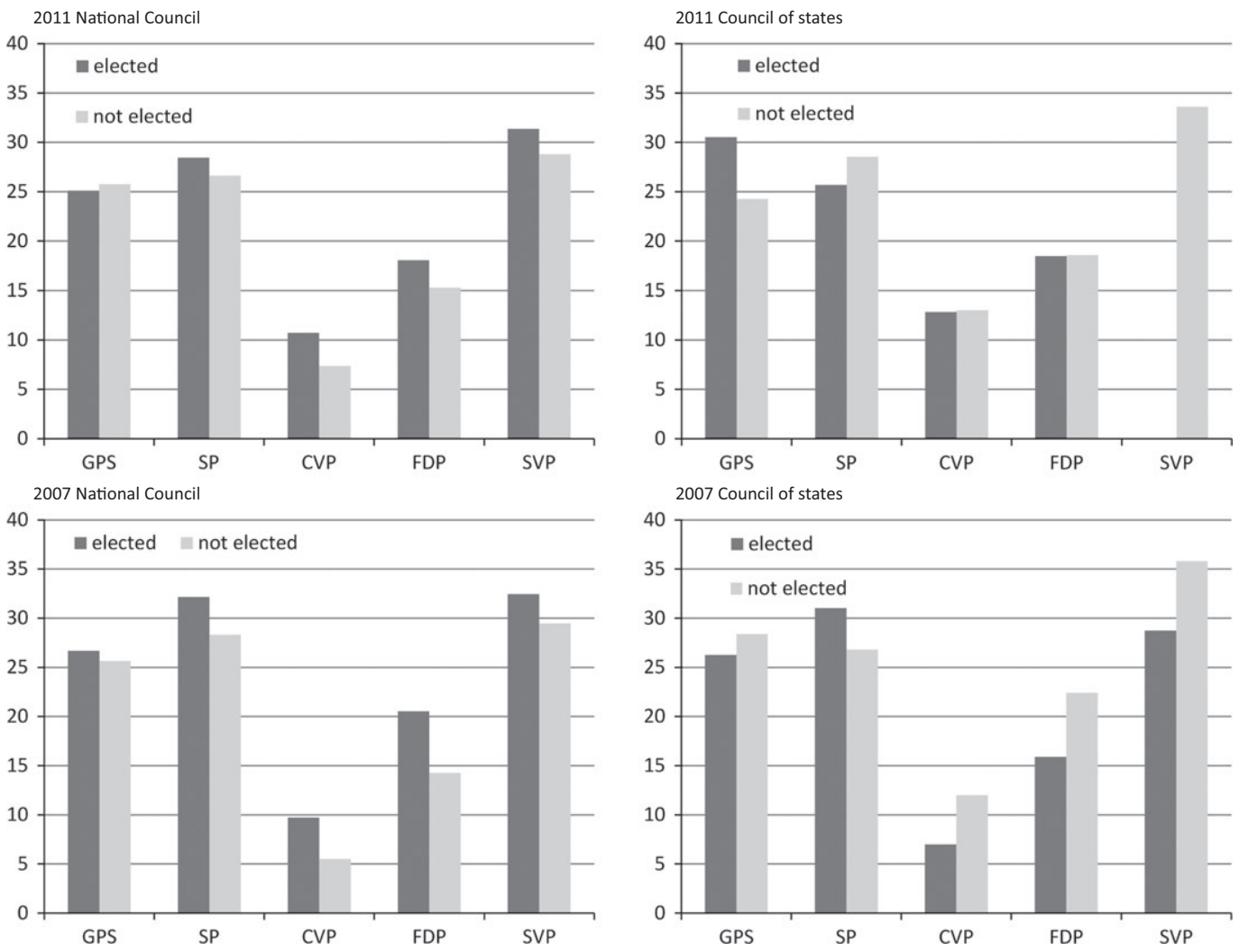

How to read the charts: If the left hand bar is higher, the elected candidates are further away from the median voter

Only cantons where real PR elections for the National Council take place: ZH, BE, AG, SG, VD and GE

N 2011 NC elected/not-elected: GPS 12/214; SP 28/245; CVP 11/189; FDP 16/249; SVP 28/140,

N 2011 CS elected/not-elected: GPS 1/5; SP 525; CVP 1/7; FDP 4/4; SVP 0/5; Voters 7900

N 2007 NC elected/not-elected: GPS 15/258; SP 25/231; CVP 15/173; FDP 16/250; SVP 37/182,

N 2007 CS elected/not-elected: GPS 2/5; SP 3/4; CVP 2/4; FDP 4/2; SVP 2/6; Voters 9180

2011 elections of the Council of States, the candidates of the Greens, the Christian Democrats, the Liberals and the Swiss People's Party could have known that the more extreme position did not pay off in 2007, nevertheless, all of them but the Greens had candidates holding more extreme positions than their fellow candidates in the National Council. For the Social Democrats the elected candidates for the Council of States in 2007 were more extreme, but their candidates in the 2011 elections were less extreme than their fellow party candidates for the National Council.

At least for the National Council the results might be an argument in favor of PR voting fostering clear positions. It remains, however unclear, why the non-elected candidates did not take such clear positions. In the literature, there is a debate around May's law on the political profile of different groups of people within the party stating 
that top leaders are more moderate than sub-leaders and non-leaders more moderate than top-leaders (May 1973). Perhaps those with real chances to win a seat in the National Council are either incumbents or sub-leaders bringing forward a clearer profile, and their party fellow candidates losing the elections belong to the non-leaders, while those getting elected at the Council of States rather belong to the top leaders and their loosing fellow party candidates to the sub-leaders.

To conclude, however, we have to admit, it is very unlikely that the Council of States has become a more polarized chamber and that the voters deliberately want to send representatives with more extreme position to this house. The astonishing result remains against all odds: Despite an electoral system which should foster more moderate positions, despite the less polarized character of the chamber and despite a lower success rate of polarized candidates, the candidates of the Council of States are in general not less extreme than their fellow party candidates for the National Council.

\section{Conclusion and discussion}

Does majority voting induce parties and candidates to bring forward more moderate positions in the course of their election campaigns? Although this looks like a simple and straightforward question, it is far from easy to come to a conclusive answer. It is extremely difficult to find a research setting where all important variables can be controlled for to make the different types of elections comparable. The Swiss elections for the Council of States and the National Council - which form together the national parliament - seem to offer an almost ideal setting to analyze this question. Both elections take place the same day, in the same electoral districts and are of almost equal importance. The only thing which differs is the electoral system, with a majority voting for the former and PR for the latter.

If theory expects majority voting to foster more moderate positions because the candidates have to convince a larger number of voters, the results are rather disappointing. Our first analysis shows that candidates running for the Council of States which is elected in a majority system do not position themselves less extremely on the leftright axis than candidates running for the National Council which is elected in a PR system. This holds also when we restrict our analysis to cantons and candidates where the difference between the two electoral systems should really matter. Comparing the elections of 2007 and 2011, there seems to be a trend towards even stronger centrifugal electoral competition for the Council of States. These results remain also valid if we rely on more encompassing ways of measuring the political differences like the positions on different policy dimensions, or if we introduce a segmented voter market and let the candidates compete on the sides of the political dimensions they are closer to.

It cannot be an increasing polarization of the Council of States either, which motivates candidates to hold more extreme positions. After the 2007 elections, the members of the Council of States were generally more moderate than the members of the National Council. The candidates for the Council of States have been too extreme and the candidates for the National Council have been relatively too moderate compared with the profiles of the houses they tried to get elected for. This led us to look at the success of the electoral campaigns: Elected members of the Council of States are generally less radical than their not elected party fellow candidates. The question therefore is: Why did not all candidates for the Council of States adopt more moderate positions in the course of their campaign to maximize their chances to get elected? For the National Council, we find a 
similar pattern pointing in the other direction. Here the elected members are more radical than the not elected ones.

Obviously, neither the character of the house they are running for, nor the electoral systems leads the candidates to follow our expectations. In respect to the theoretical debate, our findings thus rather support the position of Ezrow (2008) than the position of Dow (2010). Our results show, at least in the Swiss case and in the elections of the two houses of the national parliament, that there is no strong evidence to believe that PR increases policy extremism or that majority voting leads to more moderate issue positions. Neither is it the case that the candidates of more extremist parties have stronger incentives to adapt their positions in the direction of the median voter if they have to attract a higher percentage of the electorate to get elected. In the case of the Swiss People's Party (SVP) even the contrary seems to be the case. The drift to the right of their candidates does not astonish observers of Swiss politics, since in the 2011 elections for the Council of States the Swiss People's Party tried in vain to increase its low share of the seats by presenting their most prestigious exponents coming from the very right wing of the party. This again clearly shows that the simple claim that majority elections lead to more moderate political positions cannot be maintained. There are other motives influencing the positioning of parties and candidates as well.

The candidates do not seem to be free or willing to change their policy positions if they have to reach a bigger part of the electorate. Is it loyalty to their party which keeps them on track? Or perhaps, it is simply a lack of information about their voters. Of course, being asked, they will pretend to have a political program they stick to and they will not change their positions for electoral reasons. This might even be partly true. However, it does not make much sense to run for elections with no chances to get elected. Perhaps there are valence factors of the candidates (prestige, charisma) which play a more important role. Some candidates get elected regardless of their political positions. Or, it is the fact of being an incumbent, which allows or forces them to stick to their program?

There are two other possible explanations following different tracks and ask for more research: one is rather technical, the other concerns the voters. It would be interesting to investigate to what extend the openness of the ballot list in the Swiss PR system combines PR with majority system effects. Candidates running for the National Council compete not only against other parties, but also against members of their own party for not all candidates on the list get elected but only those with the highest number of votes. This means that candidates for the National Council can also have incentives to bring forward more moderate positions, especially if they look for votes from other parties which are closer to the center.

And as far as the voters are concerned, the question is to what extent they vote for candidates which have exactly the same issue positions as they have. If they vote strategically themselves (Lachat/Selb 2010), they might also opt for more extreme candidates in the elections for the Council of States.

Party or candidate extremism can by far not be explained through the electoral system alone. There have to be other variables to be integrated into the model, such as party strategy, the charisma of the candidates and probably also the very concrete constellation of the elections under scrutiny. Since we have found quite considerable differences in the two elections analysed, there are also good reasons to believe that the positioning of the parties and candidates may vary over time without any institutional changes, at all. 


\section{References}

Adams, J. (1999). Policy Divergence in Multiparty Probabilistic Spatial Voting. Public Choice 100: $103-22$.

Alvarez, M. and J. Nagler (2004). Party System Compactness: Consequences and Measures, Political Analysis: 46-62.

Cox, G. (1990). Centripetal and Centrifugal Incentives in Electoral Systems. American Journal of Political Science 34: 905-35.

- (1997). Making Votes Count. Cambridge: Cambridge University Press.

Curini, L. and A. Hino (2012). Missing Links in Party-System Polarization: How Institutions and Voters Matter. The Journal of Politics 74: 460-473.

Daalder, H. (1984). In Search of the Centre of European Party Systems. American Political Science Review 78(1-2): 92-109.

Dow, J. (2001). A comparative spatial analysis of majoritarian and proportional elections. Electoral Studies 20(1): 109-125.

- (2010). Party System Extremism in Majoritarian and Proportional Electoral Systems. British Journal of Political Science 41: 341-361.

Duverger, M. (1954). Political Parties. New York: Wiley.

Duverger, M. (1972). Factors in a Two-Party and Multiparty System. In Party Politics and Pressure Groups. New York: Thomas Y. Crowell (23-32).

Ezrow, L. (2008). Parties' Policy Programmes and the Dog that Didn't Bark: No Evidence that Proportional Systems Promote Extreme Party Positioning. British Journal of Political Science 38: 479-497.

Green-Pedersen, C. (2004). Centre Parties, Party Competition, and the Implosion of Party Systems: A Study of Centripetal Tendencies in Multiparty Systems. Political Studies 52: 324-341.

Kirchheimer, O. (1965). Der Wandel des westeuropäischen Parteiensystems. Politische Vierteljahresschrift 6(1): 20-41.

Lachat, R. and P. Selb (2010). Strategic Overshooting in National Council Elections. Swiss Political Science Review 16(3): 481-498.

Ladner, A., D. Schwarz and J. Fivaz (2008). Die Positionierung der Nationalratskandidierenden 2007. Eine explorative Analyse der Antworten auf die Fragen der Online-Wahlhilfe smartvote. Chavannesprès-Renens: Cahier de l'IDHEAP Nr. 243.

Ladner, A., G. Felder and J. Fivaz (2010). More than toys? A first assessment of voting advice applications in Switzerland. In Cedroni, L. and D. Garzia (eds.). Voting Advice Applications in Europe. The State of the Art. Napoli: CIVIS s.n.c/Scriptaweb (91-123).

Ladner, A. and J. Pianzola (2010). Do Voting Advice Applications Have an Effect on Electoral Participation and Voter Turnout? Evidence from the 2007 Swiss Federal Elections. In Tambouris, E., A. Macintosh and O. Glassey (eds.), Electronic Participation. Berlin, Heidelberg, New York: Springer (211-224).

Ladner, A. and J. Fivaz (2012). Voting Advice Applications. In Kersting, Norbert (ed.), Electronic Democracy. The World of Political Science - The development of the Discipline Book Series. Barbara Budrich Publischer. (177-198).

Ladner, A. (2012). Voting Advice Applications werden im Wahlkampf immer wichtiger. Es ist Zeit, dass wir uns darüber Gedanken machen". In Ziegler, B. und N., Wälti (eds.), Wahl-Probleme der Demokratie. Schriften zur Demokratieforschung. Zürich: Schulthess (91-110).

- (2014). Does die Electoral System Influence the Political Positions of Parties and Candidates? Answers from VAA-Research. In Garzia, D. and S. Marschall (eds), Matching Voters with Parties 
and Candidates - Voting Advice Applications in a Comparative Perspective. University of Essex: ECPR Press (83-96).

Lutz, G. and D. Strohmann (1998). Wahl und Abstimmungsrecht in den Kantonen. Berne: Haupt.

Lutz, G. (2008). Eidgenössische Wahlen 2007. Wahlteilnahme und Wahlentscheid. Lausanne: Selects FORS.

— (2012). Eidgenössische Wahlen 2011. Wahlteilnahme und Wahlentscheid. Lausanne: Selects FORS.

Macdonald, S. and G. Rabinowitz (1998). Solving the Paradox of Nonconvergence: Valence, Position, and Direction in Democratic Politics. Electoral Studies 17: 281-300.

May, J. (1973). Opinion Structure of Political Parties: The Special Law of Curvilinear Disparity. Political Studies 21(2): 135-151.

Merrill III, S. and J. Adams, 'Centrifugal Incentives in Multi-Candidate Elections. Journal of Theoretical Politics 14: 275-300.

Miller, G. and N. Schofield (2003). Activists and Partisan Realignment in the United States. American Political Science Review 97: 245-260.

Panebianco, A. (1988). Political Parties: Organization and Power. Cambridge and New York: Cambridge University Press.

Pianzola, J. (2013). Mirror Me. The Effect of the Voting Advice Application smartvote on Voting Preferences and Behavior of Swiss Voters. Lausanne: IDHEAP PhD.

Rabinowitz, G. and S. Macdonald (1989). A Directional Theory of Issue Voting. American Political Science Review 83(1): 93-121.

Rae, D. (1967). The Political Consequences of Electoral Laws. New Haven, Conn.: Yale University Press.

Riker, W. (1982). The Two-Party System and Duverger's Law: An Essay on the History of Political Science. American Political Science Review 76: 753-766.

Sartori, G. (1976). Parties and Party Systems - A Framework for Analysis. London/New York/ Melbourne: Cambridge University Press.

Schofield, N. (2003). Valence Competition in the Spatial Stochastic Model. Journal of Theoretical Politics 15(4): 171-183.

Schofield, N. and I. Sened (2005). Modelling the Interaction of Parties, Activists and Voters: Why Is the Political Centre so Empty? European Journal of Political Research 44: 355-390.

Schofield, N., A. Martin, K. Quinn and D. Nixon (1999). Multiparty Electoral Competition in the Netherlands and Germany: A Model Based on Multinomial Probit. Public Choice 97: 257-293.

Stokes, D. (1963). Spatial Models of Party Competition. American Political Science Review 57: 368377.

Andreas Ladner is professor for political institutions and public administration at the IDHEAP at the University of Lausanne. His areas of research include the quality of democracy, local government, institutional change, political parties and voting advice applications. Address for correspondence: University of Lausanne Quartier UNIL Mouline,CH-1015 Lausanne, Switzerland. Phone: +41 215574060 ; Fax: +41 2155740 09. Email: andreas.ladner@idheap.unil.ch 